\title{
Natural cancer-killing activity of human granulocytes
}

\author{
Wenjun Le ${ }^{1}$ and Zheng $\mathrm{Cui}^{2 *}$ \\ ${ }^{1}$ The Institute for Translational Nanomedicine, Shanghai East Hospital, Tongji University School of Medicine, China \\ ${ }^{2}$ Department of Pathology, Wake Forest University School of Medicine, USA
}

\begin{abstract}
Natural existence of cancer killing activity (CKA) predominantly in granulocytes was first discovered in the cancer-resistant mice (SR/CR mice) and later in humans. The in vitro assay conditions for CKA are different from the conventional cytotoxicity assays. An experimental therapy based on the transfusion of the collected human granulocytes from the healthy donors as the direct therapeutic agent was conceptualized previously. In this perspective, the findings of our ongoing studies are summarized in hope to help clinicians who may be interested in testing the efficacy of donor granulocytes for treating cancer. Granulocyte CKA is expected to play a protective role against cancers in humans and is affected by factors, such as age, stress, seasonality, nutrients, BCG and irradiation etc. Based on our recent findings that all the target cells tested so far have negative charges on the surface whereas normal cells are charge-neutral on the surface, we propose that the negative surface charge is the cellular property targeted by granulocytes which are the only cells with positively-charged surfaces.
\end{abstract}

\section{Introduction}

Granulocytes are the most abundant leukocyte type well known for its major role in defense against bacterial infection. Although they are often observed in cancer lesions, their roles in the immunity against cancer had always been controversial. Nevertheless, most studies on this topic were done in cancer patients where no protective function of any immunity against cancer is expected. The involvement of granulocytes in anti-cancer immunity at a decisive level was serendipitously discovered in our lab in 1999 [1]. One of normal $\mathrm{BALB} / \mathrm{c}$ mice unexpectedly survived the otherwise lethal injection of sarcoma 180 (S180). The opportunity of studying this resistance came when such a profound survivability against injection of lethal cancer cells turned out to be a germline transmissible dominant phenotype. The colony lasted for 15 years in our lab and is still being kept at another European lab [2]. Further studies demonstrated that granulocytes are solely responsible for the entire cancer-resistance by directly killing cancer cells and can be transferred to other mice to cure established malignancies [3]. The resistance was not limited to just sarcoma cells, but also other lethal cancer cell lines [4].

Based on these in vivo observations, we confirmed the cancer cell killing activity in vitro by showing that it is only present in the cancerresistant mice but not normal mice. This simple in vitro assay is unique in comparison to conventional cell killing assay in which release of radioactive materials from pre-labeled target cells was measured to determine the level of cells killed. But conventional assays were done in 4 hours. For our assay, any adherent cancer cells can be used as the target. After incubation of at least 24 hours with non-adherent effector cells, the live cells still attached to the culture surface are determined as a percentage of the control in which no effector cell is added and all target cells are alive $[3,5]$. Based on the in vivo difference between the cancerresistant mice and normal mice, the conditions of the assay in terms of co-incubation time, co-incubation temperature, the co-culture media and the choice of target cells were fine-tuned to reflect the phenotype of cancer-resistance in mice. In other words, the assay condition is set to be able to determine which mouse is cancer-resistant or not. So far, while being able to detect significant CKA in the cancer-resistant SR/
CR mice, no CKA has been detected in wild-type mice. It is apparent that this assay is able to reflect the cancer-resistant phenotype via the leukocytes collected from the peritoneum after mobilization. CKA was also detected in other cell populations of the resistant mice, primarily in the macrophage fraction, but at much lower level of specific activity. Once the assay is established to screen the cancer-resistant mice by using mouse cancer cells as targets, it was then the time to address the question whether there were humans having a similar CKA in their leukocytes.

\section{Definition of CKA}

It is not possible now to challenge humans with live cancer cells to find out who is cancer-resistant and who is not. It was done several decades ago but drew severe ethical concerns [6-8]. It is possible, however, that a blood test can be used to screen humans for an activity similar to that of the cancer-resistant mice. Our in vitro assay could be easily adapted into a simple blood test to determine the level of CKA in human leukocytes. First, leukocytes could be easily purified from human peripheral blood and be further separated into the fractions of granulocytes, monocytes, and lymphocytes. Second, there are numerous cell lines of human cancers from nearly all tissue/organ origins available as target cells. The relative levels of CKA are defined by the percentage of target cells killed by effector cells at designed effector:target cell ratios (for each assay in our lab, E:T are routinely at $3: 1,10: 1$ and $20: 1$ ) after 24 hours of co-culture at $39^{\circ} \mathrm{C}$. For example, $20 \%$ killing at $3: 1,50 \%$ killing at $10: 1$ and $70 \%$ killing at $20: 1$ can be used to make sure that CKA levels are proportional to E:T ratios. Additionally, the killing percentage at each E:T ratio can be compared to that of another individual to determine the relative level of CKA between individuals. The co-culture temperature is set at $39^{\circ} \mathrm{C}$ instead

Correspondence to: Zheng Cui, Department of Pathology, Wake Forest University School of Medicine, Winston-Salem, NC 27157, USA, E-mail: zheng.cui@gmail.com

Received: January 12, 2018; Accepted: February 04, 2018; Published: February 06,2018 
of $37^{\circ} \mathrm{C}$ because granulocytes function better and are more consistent at a high temperature that mimics fever.

\section{Distribution of CKA among different subtypes of leukocytes}

As a routine, specific CKA levels of $3 \mathrm{E}: \mathrm{T}$ ratios are measured in both granulocyte fraction and mononuclear cell fraction that contains monocytes and lymphocytes. In healthy individuals, the specific CKA level is nearly always higher in the granulocyte fraction than the mononuclear cell fraction, which is consistent with the observations in the SR/CR mice. Given the fact that granulocytes are the most abundant leukocytes in the peripheral blood, ranging from $45-70 \%$ of the total circulating leukocytes, they possess over $85 \%$ of total CKA. However, we noticed that the specific CKA level is higher in mononuclear cell fraction than in granulocyte fraction in about $15 \%$ of cancer patients. The clinical significance of this reversion in CKA distribution is still under study but maybe caused by the use of chemotherapies that affect granulocytes more significantly than mononuclear cells. It is apparent that the naturally-existing CKA is present predominantly in the granulocytes of healthy humans.

\section{Target cells of CKA assay}

Initially, we used human cervical cancer cell line, Hela cells, as the target cells. Later we extend the target cells to other human cancer cell lines. Our results show that each individual has significantly different CKA levels against different cancer cells lines, ranging from breast cancers, prostate cancers and other types of cancer tested so far (Figure 1). For example, the granulocytes collected from one individual at 10:1 E:T ratio have $60 \%$ CKA against Hela cells but have 25\% CKA against MD231. Another individual has 40\% CKA against Hela and 50\% CKA against MD231. These results suggest that the best strategy for selecting the most efficient granulocytes for killing a specific type of cancer may need to target a panel of cancer cell line of the same type of cancer. For example, a panel of breast cancer cell lines can be used to screen for potential donors for breast cancer patients, instead of using Hela cells or just one breast cancer cell line. Subjects who have the highest overall CKA against all target cell lines are expected to be the best potential donors of granulocytes for a particular patient. CKA against Hela cells appears to represent average CKA against other cancer cells as target cells in many, but not all, individuals.

Ultimately, one would hope to use the primary cancer cells collected directly from patients and representative of active cancer cell populations in patients as the target of CKA assays. However, such a hope may face several technical challenges including how to collect primary cancer cells from patients and how to perform CKA assay with the potentially non-adherent target cells.

\section{Biology of granulocytes}

Granulocytes are the first responders of the human immune system against infections. They can arrive at the sites of infection or wounds within minutes. Granulocytes have several effector mechanisms against target cells. They are phagocytes that engulf small pathogens before killing them internally $[9,10]$. Another major effector mechanism of granulocytes is the process termed degranulation, in which the cytotoxic contents of granules, such as lactoferrin, cathelicidin, myeloperoxidase, bactericidal/permeability increasing protein (BPI), defensins (also known as human neutrophil peptides), serine proteases, neutrophil elastase, cathepsin G, and gelatinase [11-14], are released to kill target cells.

Human neutrophil peptides (HNPs) are the most abundant proteins in human neutrophils. HNPs constitute $5 \%$ of total neutrophil proteins and $50 \%$ of azurophil granule proteins and are the major antimicrobial effectors [11,15-18]. HNPs contain 20-40 amino acids rich in arginine, lysine, and cysteine resulting the peptides to be positively-charged and called "cation peptides" [19].

HNPs have an amphipathic folded rod-like structure with one side being hydrophobic and the other side being hydrophilic and positively charged [20,21]. It has been proposed that the primary targets of HNPs are the negatively-charged lipid bilayer membranes [11]. The activation mechanism of HNPs is the cleavage of negatively charged leader peptides that neutralize the positive charges in the peptide precursor [11].

On target cells, the mature amphipathic HNPs exert two major effector actions. First, HNPs form barrel-like pores on plasma membranes of target cells [11]. The hydrophobic side of the monomeric HNP lines up against the hydrophobic portion of the target bilayer membranes whereas the hydrophilic side of the HNP forms a hydrophilic pore with other similarly lined-up HNPs. The holes cause swelling and rupture (cytolysis) of target cells. Second, HNPs, once they enter the cytoplasm of target cells that contain mitochondria, can bind to and neutralize the negatively-charged outer mitochondrial membranes, leading to dissipation of the mitochondrial transmembrane potential, a well-known mechanism for triggering rapid apoptosis [22].

\section{Granulocytes:Hela=10:1, Percentage of Hela Cells Killed in 24 hours (CKA)}

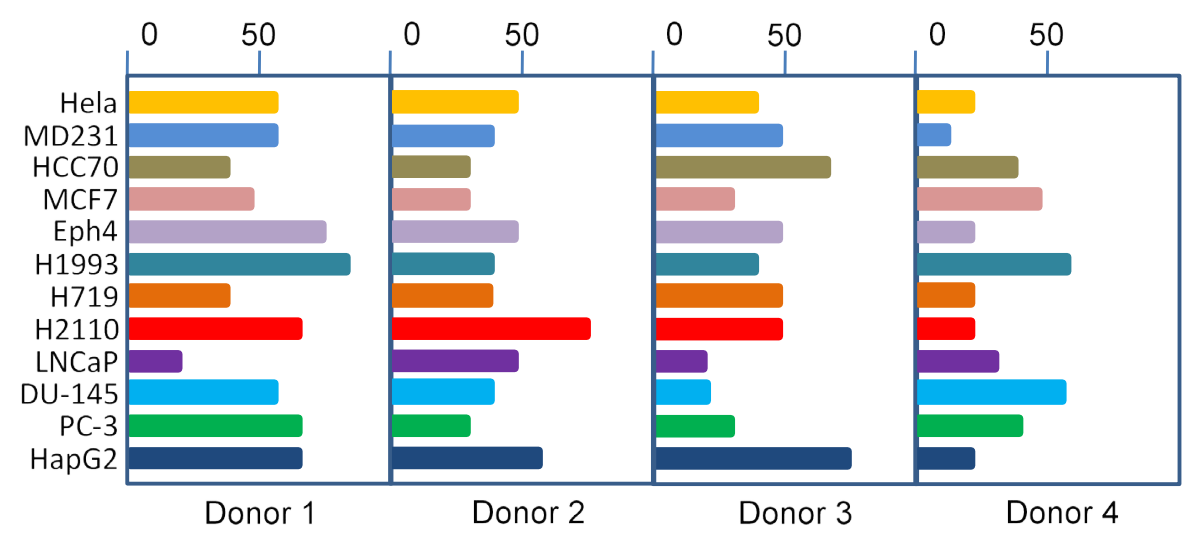

Figure 1. Spectrum of target cells of granulocyte CKA. 


\section{CKA variability in different individuals}

After last 13 years since CKA assay was established to screen human blood samples, more than 1000 subjects have been evaluated. Here some of the general trends of CKA in human populations are summerized. The most important finding is that there is a great individual variability of CKA from individual to individual and even from time to time in the same individual. There is a normal distribution of CKA in the human population studied so far. At 10:1 E:T ratio, most healthy people have CKA in the range of $40 \%$ and $60 \%$ CKA against Hela. Less than $10 \%$ of human have CKA higher than $80 \%$. Less than $1 \%$ have CKA higher than $90 \%$. One interesting observation is that a 20-years old female subject had 95\% CKA and her 52-year old mother had $97 \%$ CKA. Genetic pattern of CKA in human populations has not been studied. Sex and race have no apparent impact on CKA.

\section{CKA in cancer patients and in healthy people}

In mice, the ability to survive the lethal challenges of cancer cells was entirely determined by having CKA or not. CKA may also be an activity for protecting humans from developing cancer. One would expect that CKA might be compromised in cancer patients in the first place. We compared the CKA against Hela cells in over 50 healthy individuals and over 50 cancer patients of ages between 45 and 65. At 10:1 ET ratio, the average CKA against Hela cells is $50 \%$ for healthy people and $30 \%$ for cancer patients. We expect that the future CKA results against the cell lines similar to the cancer types of the patients may be more interesting. These results suggest that good CKA should come from the granulocytes of healthy people, not from other cell fractions or any leukocyte fractions of cancer patients. If the leukocytes of cancer patients were effective at all against cancer cells, they should not have gotten the disease in the first place. It would be even more interesting to compare the CKA against their own cancer cells by the granulocytes of cancer patients and of healthy donors. However, this experiment may have to wait till a large number of primary cancer cells can be isolated and used as the target cells of the assay. Such a technical ability is currently unavailable.

\section{CKA in different age-groups}

Aging is the greatest impact factor for cancer development. Aging also has a significant impact on the cellular immunity in general. We also compared CKA against Hela cells of over 100 healthy young subjects between age 20 and 30 to over 40 healthy old subjects between age 67-76 with mixed sexes and races. The average CKA is $65 \%$ for the young subjects and $40 \%$ for the old subjects. Yet, the individual variability is bigger in the old group than the young group. This finding is consistent with the possibility that the age-related increase in cancer incident rate is associated with the age-related decrease in CKA.

\section{Effect of stress on CKA}

Stress is an inevitable part of modern society and harms humans and animals. There is a common belief that stress promotes or even causes cancer [23]. However, the scientific evidence in supporting such a belief is weak [24-32]. The human body deals with acute stress with stress response or "fight-or-flight" response, in which stress hormones are released into the blood stream [33-34]. As a result, stress hormones stimulate energy utilization in the stress response organs, such as cardiac, pulmonary, muscular and sensory systems and inhibit energy metabolism in the non-response organs, such as digestive, renal and immunological systems [35-37]. Among stress hormones, cortisol, epinephrine, and norepinephrine are the quantitatively most important molecules released into blood stream $[38,39]$. The inhibitory effects of these stress hormones on the immunological system have been wellestablished and also been utilized widely in suppressing over-reaction of the cellular immune system, such as allergic reactions [40-46].

We measured CKA against Hela cells in a group of students before, during and after a final exam of the semester. This is a previously established model of having a group of subjects undergoing a shortterm psychological stress synchronously [47]. In our experiments, CKA was nearly abolished in the exam days in all tested subjects and quickly returned to previous levels a few days after exams. This suppression of CKA was accompanied by rises of stress hormones in the blood.

In vitro studies also showed that the major stress hormone, cortisol, had more profound inhibitory effects on granulocyte CKA than other two major stress hormones: epinephrine and norepinephrine.

Complete abolishment of CKA and subsequent recovery were also serendipitously observed following incidental stressful events such as heated argument or public speaking by a student.

\section{Seasonality of CKA}

However unexpected, the seasonality of CKA in granulocytes in North Carolina (latitude $38^{\circ} \mathrm{N}$ ) is unequivocally clear and profound (Figure 2). CKA is completely absent between October and March. CKA returns in April. We detected CKA in some samples collected in November and in February in Miami, Florida (latitude $25^{\circ} \mathrm{N}$ ) and shipped to North Carolina via overnight express mail for the assay. We also detected CKA in a small portion of samples collected in Shanghai (latitude $38^{\circ} \mathrm{N}$ ) during the winter months when there is no CKA at all in North Carolina. We suspect that there might be unknown CKA stimulants present in the environment.

The seasonality of cellular functions in humans at such a profound level is unexpected. Early humans had to deal with the significant shortage of food in the winters by sleeping more and eat less. The energy expenditure in hibernating animals in the winters can drop to $1 / 20$ of their summer levels [48]. In humans, the energy expenditure in the winters can drop to a fraction of the summer level. Most modern humans gain weights during winter months as a result of reduced expenditure if the food intake remains unchanged.

One practical implication of this result is that the winter may not be a good time to find donors with high levels of granulocyte CKA.

\section{Effects of nutrients on CKA}

There are 39 essential nutrients required for the growth of human cells in cell culture and probably for the growth of infants in the first

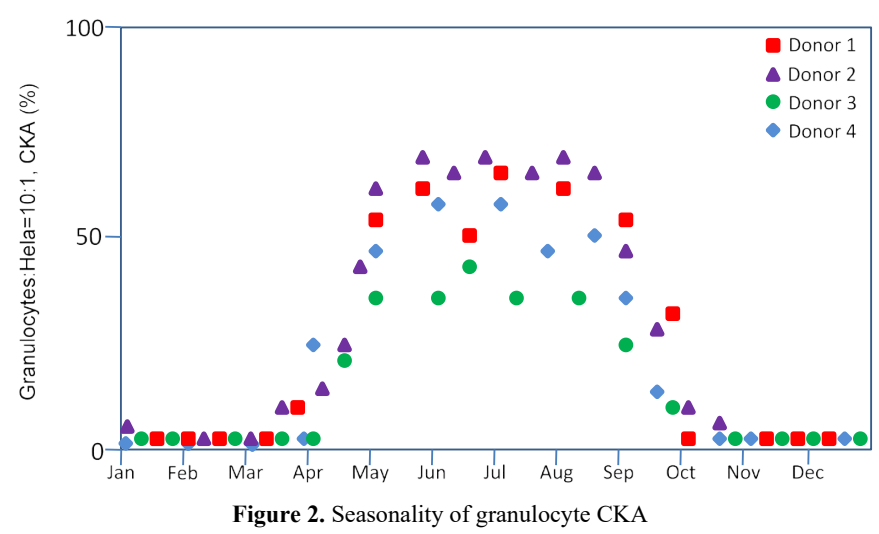


4-6 months before they have to turn to solid food. Probably by then, the ability of endogenous synthesis of cellular constituents begins to decline and buildup of cells in the body relies more and more on additional nutrients in solid food. There is probably no upper limit how many nutrients cells in the body may need to achieve ultimate functions. But one might safely assume that the more nutrients are available, the better cells will function.

To find nutrients that can specifically boost granulocyte CKA, we screened up to 60 different fruits and vegetables. We found that human granulocyte CKA was elevated by at least $100 \%$ by the cold water extracts of jalapeno, beet root or baby Bella mushroom after high-speed blending. The in vivo effects of these potential stimulants on CKA have yet to be determined. We are also not sure whether the CKA stimulation is affected by dietary history in the last few days leading up to the blood draws. For example, if the donor had eaten a lot of apples but had not eaten jalapeno for a long time before the blood draw, jalapeno may stimulate CKA because of its long absence from the diet but not because it is a specific stimulator. We wonder whether apple would have similar stimulation if it is absent from diet before the blood draw due to nutrient craving at cellular levels.

\section{Effects of BCG on CKA}

Bacillus is a genus of Gram-positive, rod-shaped bacteria that are known to cause tuberculosis. BCG is a strain of Bacillus bacteria developed by the French scientists Calmette and Guérinin between 1908 and 1921 to achieve the attenuated virulence via serial passages of bacterial cultures [49]. This strain was named Bacillus CalmetteGuérinand and had been used as vaccines for tuberculosis and leprosy. With the reduced virulence, injection of live bacteria into humans became much safer. In the 1950s, it was demonstrated that live BCG could benefit mice bearing lethal transplanted cancer cells [50]. BCG was used clinically in treating human bladder cancers resulting in significant efficacy [51].

Intravesical live Bacillus Calmette-Guérin (BCG) is the most effective therapy for bladder cancer carcinoma in situ. Live bacillus bacteria with reduced virulence are instilled into the bladder as the therapeutic agent. Forty years after its first report [51], BCG therapy still remains the treatment of choice due to its high response rate and lower incidence of severe side effects in comparison to cytotoxic intravesical chemotherapies. The response rate of the bladder carcinomas to BCG therapy can be as high as 75\% [52], making it the most successful therapy in existence against solid cancers. However, after over 100 million doses in last several decades, the effector mechanism of the BCG therapy still remains peculiarly elusive.

The usage of live bacteria to treat cancer has a long history. In the late $19^{\text {th }}$ century, there were numerous observations of miraculous regression of late-stage cancer triggered by severe infections with severe febrile responses [53]. Intrigued, William Coley began to treat cancer patients intentionally with live bacteria collected from the sites of infection. He first reported in 1891 that intentional administration of live bacteria into the tumors induced similar infections, febrile responses and tumor regressions in human but not without a high rate of sepsis [54].

Granulocytes are known to be highly responsive to bacterial infection. It is possible that mechanism of BCG treatment is mediated by stimulation of granulocytes that in turn kill bladder cancer cells. We screened a group of bladder CIS patients treated by BGC for CKA before and after a conventional 6-week BCG therapy. We found that
CKA in granulocytes was elevated by at least $50 \%$ in the patients who responded well clinically to BCG therapy. This result is also consistent with the possibility that the efficacy of BCG therapy is mediated mechanistically by granulocyte CKA.

\section{Effects of irradiation on CKA}

In clinical practice of transfusion, allogeneic blood cells are often irradiated to block donor cell proliferation that causes possible graftvs-host diseases, especially for the immune-compromised patients. Our results showed that irradiation reduced CKA of granulocytes to $1 / 3$. Irradiation breaks up cellular DNA into fragments not only to prevent DNA replication for cell division but also to block many cellular functions that require nascent synthesis of RNA and protein. Therefore, it is not surprising that CKA of granulocytes is diminished by irradiation.

\section{Recognition mechanism by granulocytes via surface charge}

The fact that human granulocytes can recognize a vastly different array of cancer cells and bacteria without prior exposure suggests that the possible target on the surface of cancer cells and bacteria is probably not molecularly-based. We tested whether cancer cells might be unique in surface charges.

Bioelectricity is a critical part of all life forms [55-57]. However, the electrical properties of somatic cells in animals remain poorly understood. As early as in the 1940s, some very subtle behaviors of cancer cells led to the suspicion that their surfaces may be electrically different from that of normal cells. These cellular behaviors include stickiness with neighboring cells, loss of contact inhibition of cell growth and formation of cancer cell aggregates by cationic polymer polyethyleneimine (PEI) [58]. These findings also led to the numerous studies of cell surface charges by cell electrophoresis [59]. However, this methodology of measuring cell surface charge was highly insensitive, with inconsistent results from different laboratories [60]. The extremely high surface charge-to-mass ratio required to move cells directionally in an electrophoretic field cannot be achieved by most cells in a given cell population. A major problem for cell electrophoresis is that few cells moved and were counted; most cells remained stationary. Technical challenges of how to accurately measure the surface charges of somatic cells may have caused the field to be stagnant for several decades. The few early claims that cancer cells may have unique surface charges were not further validated or extended beyond an evaluation of a few cell lines and no application had been developed.

We designed two nanoprobes (NPs), one with a positively charged surface and the other a negatively charged surface, that may have resolved the aforementioned problems [61]. Both types of NPs carried two additional properties of being able to capture the attached cells by a magnet and of being identifiable by fluorescence.

NPs can be used to measure surface charges of many cells types, including cancer cells from established cell lines and normal cells isolated from fresh tissues and peripheral blood. All tested cancer cells bound exclusively to the positive NPs (Figure 3, previously published [61]). Except for granulocytes, normal cells had no binding to either type of NPs $[61,62]$. The negative surface charges are highly sensitive to inhibition of glycolysis and are generated as a result of lactate secretion.

In addition to all culture cancer cells having the negative surfaces, recently we were able to capture large numbers of cancer cells from the peripheral blood samples of patients with metastatic cancers and 


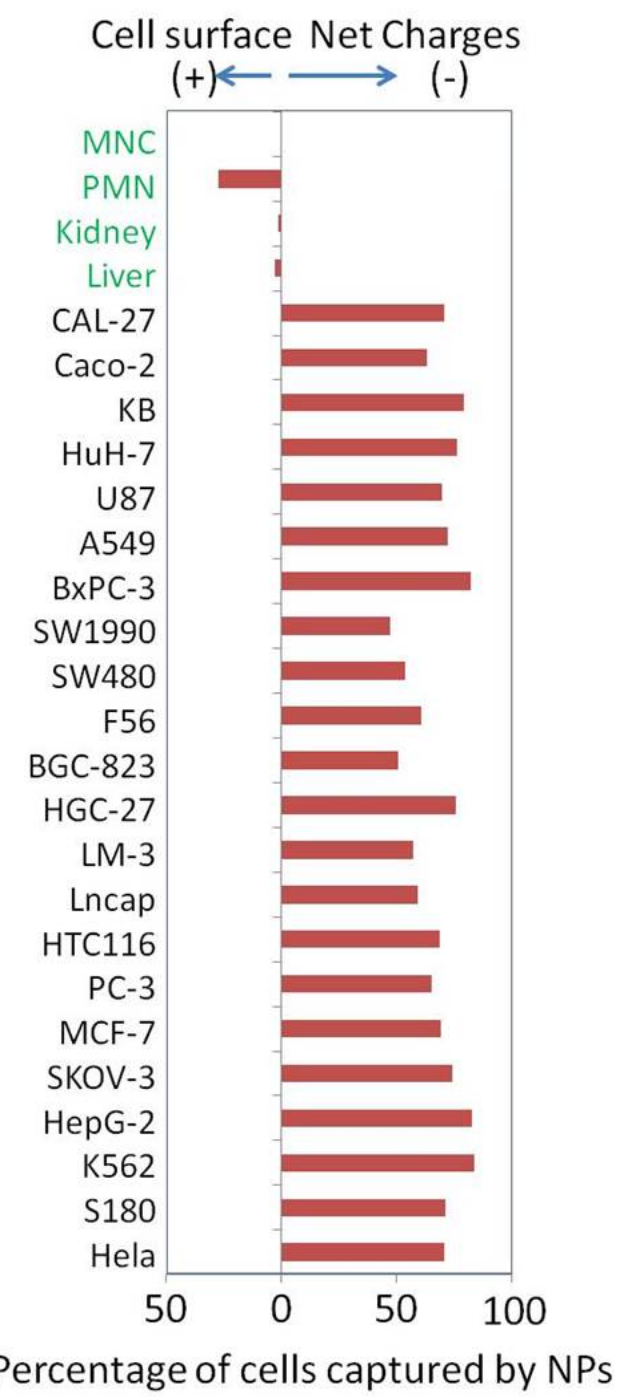

Figure 3. Surface charge of cancer cells and normal cells

leukemia by using a newly developed CTC capture nanotechnology also based on the unique surface charge of cancer cells. These findings suggest that negative surface charge is a unique property of all tested cancer cells of both in vitro and in vivo sources. We, therefore, propose that this unique surface electrical property of cancer cells may be the target for recognition by granulocytes.

With the same methodology, granulocytes were found to be the only cells we tested so far for having positive surfaces. Such an opposite surface charge would allow granulocytes to attach to cancer cells easily and specifically without having to have any other molecular mechanism and to avoid normal cells that were all charge-neutral.

To functionally validate whether the surface charge is required for CKA, we used the positively charged NPs to shield the surface charges of target cancer cells before mixing with granulocytes. As a result, granulocyte CKA was effectively blocked.

Using the same methodology, we also found the surface of E.coli was also negatively charged, which is consistent with many previous reports of bacteria having negatively charged surfaces. We propose that recognition of bacteria by granulocytes may also be mediated by the opposing surface charges.

\section{Conclusion and outlook}

In 2008, we proposed a new cancer therapeutic concept of a CKAbased allogeneic granulocyte transfusion. The key components of this therapeutic concept are to find healthy donors with high levels of granulocyte CKA, collect granulocytes via apheresis after mobilization and transfuse the freshly collected granulocytes to cancer patients. This concept is fundamentally different from all previous immunotherapies for cancer in nearly all key aspects. A few clinical trials initiated by investigative clinicians were approved in the US by FDA in 2009. Similar trials were also initiated later in several other countries. However, due to a lack of funding and inability of collecting complete, key follow-up data after treatment, no meaningful progress that met the criteria of the original study design can be reported from these clinical efforts at this time. Out of several hundred infusions of donor granulocytes known to this lab, no GVHD has occurred, suggesting that the therapy is safe.

There is one special case with complete data worthy of describing. A 52-year old female patient was diagnosed with stage IV squamous cell carcinoma/adenocarcinoma without a known origin. Innumerous metastatic lesions were found in the lungs, liver, ovaries and pelvic cavity. She was treated with 7 rounds of exploratory taxol/carbo chemotherapy before severe pulmonary and cardiac allergic reactions were developed. It was followed by a pelvic debulking surgery with ovariohysterectomy for temporary relief of pelvic symptoms. Due to the massive metastasis to liver and lungs and the well-documented non-responsiveness of squamous cell carcinoma to chemotherapies in the literature, the survival time was estimated to be 3-6 months. Without any conventional treatment option after surgery, she was treated with the donor granulocyte therapy on a compassionate basis. Twenty young volunteers (college students) of the same blood type were initially screened by interviewing heath history of self and blood-related family members. Ten volunteers selected after the interviews had blood draws $(8 \mathrm{cc}$ ) for testing granulocyte CKA. One 20 -year-old volunteer had an exceptionally high level of granulocyte CKA at $86 \%$ with 10:1 E:T ratio against Hela cells and agreed to be the donor of granulocytes. The donor was mobilized by $300 \mu \mathrm{g} \mathrm{G-CSF}$ and $8 \mathrm{mg}$ dexamethasone i.m. 12 hours before apheresis collection of granulocytes. The final yield of the collected leukocyte concentrate was $2.2 \times 10 \mathrm{e} 10$ granulocytes with $60 \%$ purity in 300 -cc volume. All the collected granulocytes were immediately infused i.v. to the patient within 3 hours. After the infusion, the patient had a prolonged fever between 39 and $40^{\circ} \mathrm{C}$ for 10 days. Such a long-lasting high fever was highly unusual for normal blood transfusion and was intentionally left untreated by medication. There has never been any symptom related to either the disease or the treatment since the treatment. It has been four years since the one-time granulocyte infusion as the last and the only treatment. She has been monitored by chest and abdominal CT scans every 6 months for first 30 months and every 12 months later. Most metastatic lesions in the lungs and liver are still visible on the CT scans but stable for the last 4 years. She has had very active daily physical exercises and had no complaints of any symptom for the last 4 years.

Clinically, the donor granulocyte therapy is no more difficult than giving a blood transfusion. The key to success may largely rely on finding donors with high levels of direct therapeutic activity. The future of this therapeutic concept is completely up to clinicians and funding agencies. Correct or not, this concept is a new direction different from other immunotherapies and is supported by good common sense and by a great amount of laboratory efforts worth millions of dollar cumulatively. It would be a great waste if only few patients benefited from all the prior investigative efforts. 


\section{References}

1. Cui Z, Willingham MC, Hicks AM, Alexander-Miller MA, Howard TD, et al. (2003) Spontaneous regression of advanced cancer: Identification of a unique genetically determined, age-dependent trait in mice. Proc Natl Acad Sci U S A 100: 6682-6687. [Crossref]

2. Koch J, Hau J, Pravsgaard Christensen J, Jensen HE, Hansen MB, et al. (2013) Immune cells from $\mathrm{SR} / \mathrm{CR}$ mice induce the regression of established tumors in BALB/c and C57BL/6 mice. PLoS One 8: e59995. [Crossref]

3. Hicks AM, Riedlinger G, Willingham MC, Alexander-Miller MA, Von Kap-Herr C, et al. (2006) Transferable anticancer innate immunity in spontaneous regression/complete resistance mice. Proc Natl Acad Sci U S A 103: 7753-7758. [Crossref]

4. Riedlinger G1, Adams J, Stehle JR Jr, Blanks MJ, Sanders AM, et al. (2010) The spectrum of resistance in SR/CR mice: the critical role of chemoattraction in the cancer/ leukocyte interaction. BMC Cancer 10: 179. [Crossref]

5. Blanks MJ, Stehle JR Jr, Du W, Adams JM, Willingham MC, et al. (2011) Novel Innate Cancer Killing Activity in Humans. Cancer Cell Int 11: 26-33. [Crossref]

6. MOORE AE, RHOADS CP, SOUTHAM CM (1957) Homotransplantation of human cell lines. Science 125: 158-160. [Crossref]

7. SOUTHAM CM (1958) Homotransplantation of human cell lines. Bull N Y Acad Med 34: 416-423. [Crossref]

8. Lerner BH (2004) Sins of omission--cancer research without informed consent. N Engl $J$ Med 351: 628-630. [Crossref]

9. Nathan C (2006) Neutrophils and immunity: challenges and opportunities. Nat Rev Immunol 6: 173-182. [Crossref]

10. Witko-Sarsat V, Rieu P, Descamps-Latscha B, Lesavre P, Halbwachs-Mecarelli L (2000) Neutrophils: molecules, functions and pathophysiological aspects. Lab Invest 80: 617-653. [Crossref]

11. Lehrer RI, Lichtenstein AK, Ganz T (1993) Defensins: antimicrobial and cytotoxic peptides of mammalian cells. Annu Rev Immunol 11: 105-128. [Crossref]

12. 12. Lichtenstein AK, Ganz T, Selsted ME, Lehrer RI (1988) Synergistic cytolysis mediated by hydrogen peroxide combined with peptide defensins. Cell Immunol 114: 104-116. [Crossref]

13. Zanetti M, Gennaro R, Romeo D (1995) Cathelicidins: a novel protein family with a common proregion and a variable $\mathrm{C}$-terminal antimicrobial domain. FEBS Lett 374: 1-5. [Crossref]

14. Dale DC, Boxer L, Liles WC (2008) The phagocytes: neutrophils and monocytes. Blood 112: 935-945. [Crossref]

15. De Smet, K, Contreras R (2005) Human antimicrobial peptides: defensins, cathelicidins and histatins. Biotechnol Lett 27: 1337-1347. [Crossref]

16. Lehrer RI (2004) Primate defensins. Nat Rev Microbiol 2: 727-738. [Crossref]

17. Rice WG, Ganz T, Kinkade JM Jr, Selsted ME, Lehrer RI, et al. (1987) Defensin-rich dense granules of human neutrophils. Blood 70: 757-765. [Crossref]

18. Ganz T, Selsted ME, Szklarek D, Harwig SS, Daher K, et al. (1985) Defensins. Natural peptide antibiotics of human neutrophils. J Clin Invest 76: 1427-1435. [Crossref]

19. Selsted ME, Harwig SS (1989) Determination of the disulfide array in the human defensin HNP-2. A covalently cyclized peptide. J Biol Chem 264: 4003-4007. [Crossref]

20. Hill CP, Yee J, Selsted ME, Eisenberg D (1991) Crystal structure of defensin HNP-3, an amphiphilic dimer: mechanisms of membrane permeabilization. Science 251: 14811485. [Crossref]

21. White SH, Wimley WC, Selsted ME (1995) Structure, function, and membrane integration of defensins. Curr Opin Struct Biol 5: 521-527. [Crossref]

22. Green DR, Reed JC (1998) Mitochondria and apoptosis. Science 281: 1309-1312. [Crossref]

23. Willcox SJ, Stewart BW, Sitas F (2011) What factors do cancer patients believe contribute to the development of their cancer? (New South Wales, Australia). Cancer Causes Control 22: 1503-1511. [Crossref]

24. Duijts SF, Zeegers MP, Borne BV (2003) The association between stressful life events and breast cancer risk: a meta-analysis. Int J Cancer 107: 1023-1029. [Crossref]

25. Lillberg K, Verkasalo PK, Kaprio J, Teppo L, Helenius H, et al. (2003) Stressful life events and risk of breast cancer in 10,808 women: a cohort study. Am J Epidemiol 157: 415-423. [Crossref]
26. Geyer S (1991) Life events prior to manifestation of breast cancer: a limited prospective study covering eight years before diagnosis. J Psychosom Res 35: 355-363. [Crossref]

27. Michael YL, Carlson NE, Chlebowski RT, Aickin M, Weihs KL, et al. (2009) Influence of stressors on breast cancer incidence in the Women's Health Initiative. Health Psychol 28: 137-146. [Crossref]

28. Chida Y, Hamer M, Wardle J, Steptoe A (2008) Do stress-related psychosocial factors contribute to cancer incidence and survival? Nat Clin Pract Oncol 5:466-475. [Crossref]

29. Kroenke CH, Kubzansky LD, Schernhammer ES, Holmes MD, Kawachi I (2006) Social networks, social support, and survival after breast cancer diagnosis. J Clin Oncol 24: 1105-1111. [Crossref]

30. Sprehn GC, Chambers JE, Saykin AJ, Konski A, Johnstone PA (2009) Decreased cancer survival in individuals separated at time of diagnosis: critical period for cancer pathophysiology? Cancer 115: 5108-5116. [Crossref]

31. Nakaya N (2014) Effect of psychosocial factors on cancer risk and survival. $J$ Epidemiol 24: 1-6. [Crossref]

32. Coyne JC, Ranchor AV, Palmer SC (2010) Meta-analysis of stress-related factors in cancer. Nat Rev Clin Oncol 7. [Crossref]

33. Chrousos GP (2009) Stress and disorders of the stress system. Nat Rev Endocrinol 5: 374-381. [Crossref]

34. McEwen BS (2007) Physiology and neurobiology of stress and adaptation: central role of the brain. Physiol Rev 87: 873-904. [Crossref]

35. Vinik AI, Maser RE, Ziegler D (2011) Autonomic imbalance: prophet of doom or scope for hope? Diabet Med 28: 643-651. [Crossref]

36. Heim C, Ehlert U, Hellhammer DH (2000) The potential role of hypocortisolism in the pathophysiology of stress-related bodily disorders. Psychoneuroendocrinology 25 : 1-35. [Crossref]

37. Hannibal KE, Bishop MD (2014) Chronic stress, cortisol dysfunction, and pain: a psychoneuroendocrine rationale for stress management in pain rehabilitation. Phys Ther 94: 1816-1825. [Crossref]

38. McEwen BS (2002) Sex, stress and the hippocampus: allostasis, allostatic load and the aging process. Neurobiol Aging 23: 921-939. [Crossref]

39. Antoni MH, Lutgendorf SK, Cole SW, Dhabhar FS, Sephton SE, et al. (2006) The influence of bio-behavioural factors on tumour biology: pathways and mechanisms. Nat Rev Cancer 6: 240-248. [Crossref]

40. Reiche EM, Nunes SO, Morimoto HK (2004) Stress, depression, the immune system, and cancer. Lancet Oncol 5: 617-625. [Crossref]

41. Dhabhar FS, McEwen BS (1997) Acute stress enhances while chronic stress suppresse cell-mediated immunity in vivo: a potential role for leukocyte trafficking. Brain Behav Immun 11: 286-306. [Crossref]

42. Elenkov IJ (2002) Systemic stress-induced Th2 shift and its clinical implications. Int Rev Neurobiol 52: 163-186. [Crossref]

43. Glaser R, MacCallum RC, Laskowski BF, Malarkey WB, Sheridan JF, et al. (2001) Evidence for a shift in the Th-1 to Th- 2 cytokine response associated with chronic stress and aging. J Gerontol A Biol Sci Med Sci 56: M477-482. [Crossref]

44. Levy S, Herberman R, Lippman M, d'Angelo T (1987) Correlation of stress factors with sustained depression of natural killer cell activity and predicted prognosis in patients with breast cancer. J Clin Oncol 5: 348-353. [Crossref]

45. Sternberg EM, Chrousos GP, Wilder RL, Gold PW (1992) The stress response and the regulation of inflammatory disease. Ann Intern Med 117: 854-866. [Crossref]

46. Boumpas DT, Chrousos GP, Wilder RL, Cupps TR, Balow JE (1993) Glucocorticoid therapy for immune-mediated diseases: basic and clinical correlates. Ann Intern Med 119: 1198-1208. [Crossref]

47. Kiecolt-Glaser JK, Glaser R, Strain EC, Stout JC, Tarr KL, et al. (1986) Modulation of cellular immunity in medical students. J Behav Med 9: 5-21. [Crossref]

48. Watts PD, Oritsland NA, Jonkel C, Ronald K (1981) Mammalian hibernation and the oxygen consumption of a denning black bear (Ursus americanus). Comparative Biochemistry and Physiology A 69: 121-123.

49. Calmette A (1931) Preventive vaccination against tuberculosis with BCG. Proc Roy Soc Med 24: 85-94. [Crossref]

50. Old LJ, Clarke DA, Benacerraf B (1959) Effect of Bacillus Calmette-Guerin infection on transplanted tumours in the mouse. Nature 184: 291-292. [Crossref] 
51. Morales A, Eidinger D, Bruce AW (1976) Intracavitary Bacillus Calmette-Guerin in the treatment of superficial bladder tumors. J Urol 116: 180-183. [Crossref]

52. Alexandroff AB, Jackson AM, O'Donnell MA, James K (1999) BCG immunotherapy of bladder cancer: 20 years on. Lancet 353: 1689-1694. [Crossref]

53. Busch W (1867) Aus der sitzung de medicinischen section vom. Berl Klin Wochenschr 5: $137-145$.

54. Coley WB II (1891) Contribution to the Knowledge of Sarcoma. Ann Surg 14: 199220. [Crossref]

55. Presman A (1970) Electromagnetic fields and life. ISBN: 9781475706376 , Springer.

56. Delmar M (2006) Bioelectricity. Heart Rhythm 3: 114-119. [Crossref]

57. Gouaux E, Mackinnon R (2005) Principles of selective ion transport in channels and pumps. Science 310: 1461-1465. [Crossref]
58. Ambrose E, Easty DM, Jones PC (1958) Specific reactions of polyelectrolytes with the surfaces of normal and tumour cells. Br J Cancer 12: 439-447. [Crossref]

59. Ambrose EJ, James AM, Lowick JH (1956) Differences between the electrical charge carried by normal and homologous tumour cells. Nature 177: 576-577. [Crossref]

60. Gallin JI, Durocher JR, Kaplan AP (1975) Interaction of leukocyte chemotactic factors with the cell surface. I. Chemotactic factor-induced changes in human granulocyte surface charge. J Clin Invest 55: 967-974. [Crossref]

61. Chen B, Le W, Wang Y, Li Z, Wang D, et al. (2016) Targeting Negative Surface Charges of Cancer Cells by Multifunctional Nanoprobes. Theranostics 6: 1887-1898. [Crossref]

62. Han X, Deng Z, Yang Z, Wang Y, Zhu H, et al. (2016) Biomarkerless Cancer Cell Targeting and Instant Photothermal Cell Killing by a Surface-Electrically-Charged Superparamagnetic Nanocomposite. Nanoscale 9: 1457-1465.

Copyright: $\bigcirc 2018$ Le W. This is an open-access article distributed under the terms of the Creative Commons Attribution License, which permits unrestricted use, distribution, and reproduction in any medium, provided the original author and source are credited. 